\title{
PROCESSOS DE URBANIZAÇÃO E DEGRADAÇÃO AMBIENTAL URBANA: PROBLEMATIZAÇÃO NO CONTEXTO DA EDUCAÇÃO DE JOVENS E ADULTOS
}

\author{
Tanise Paula Novello ${ }^{1}$ \\ Kelly Silva Porto ${ }^{2}$
}

\section{RESUMO}

Esse artigo tem como objetivo analisar como se dá a inserção da educação ambiental no ensino de jovens e adultos a partir da problematização dos processos de urbanização e degradação ambiental urbana no município de Capão da Canoa (RS). Os instrumentos utilizados para coleta de dados foram questionários (objetivos e subjetivos) para os alunos, teste da pegada ecológica e debates. O envolvimento e participação dos alunos trouxe o movimento de pertencimento, de reflexões históricas, sociais e ambientais sobre a sua comunidade. A educação ambiental oferece condições de educar para a cidadania, para o pensamento crítico e político a respeito de problemas sociais e locais que aquela comunidade enfrenta. $\mathrm{O}$ teste da pegada ecológica possibilitou uma análise comparativa aos países desenvolvidos, as condições sociais e ambientais de cada um em relação aos alunos da turma, uma vez que o resultado foi menor que estes locais onde o uso dos recursos naturais e o descarte de resíduos. Conclui-se, a partir das ações desenvolvidas, que o resultado mais importante dessa pesquisa é a

${ }^{1}$ Doutora em Educação Ambiental pela Universidade Federal do Rio Grande - FURG. Professora do Programa de Pós Graduação em Educação em Ciências - FURG. Professora Associada da Universidade Federal de Pelotas - UFPel do Instituto de Física e Matemática IFM. ORCID: https://orcid.org/0000-0002-9585-6893.

E-mail: tanisenovello@hotmail.com.

${ }^{2}$ Mestranda do Programa de Pós-graduação no Ensino de Ciências Exatas da Universidade Federal do Rio Grande - FURG. Grupo de Pesquisa Formação de Professores na Perspectiva da Construção Curricular. Professora de Ciências da Natureza da Secretaria de Educação do Estado de Santa Catarina. ORCID: https://orcid.org/0000-0002-57278156. E-mail: kellyportoconsultoria@gmail.com. 
emergência do quanto se faz necessário espaços de vivência em Educação Ambiental em todos os níveis de escolaridade e segmentos da sociedade, promovendo reflexões e possibilitando ações de transformação de suas realidades.

Palavras-chave: Degradação Ambiental. Educação Ambiental. Ensino de Jovens e Adultos.

\section{URBANIZATION PROCESSES AND URBAN ENVIRONMENTAL DEGRADATION: PROBLEMATIZATION IN THE CONTEXT OF YOUTH AND ADULT EDUCATION}

\section{ABSTRACT}

This article aims to analyze the insertion of environmental education in youth and adult education from the problematization of urbanization processes and urban environmental degradation in the municipality of Capão da Canoa (RS). The instruments used for data collection were questionnaires (objective and subjective) for the students, ecological footprint tests and debates. The involvement and participation of the students brought the movement of belonging, of historical, social and environmental reflections about their community. Environmental education offers conditions to educate for citizenship, for critical and political thinking about social and local problems that that community faces. The ecological footprint test enabled a comparative analysis to developed countries, the social and environmental conditions of each in relation to the students of the class, since the result was lower than these places where the use of natural resources and waste disposal. It is concluded, from the actions developed, that the most important result of this research is the emergence of how much is necessary spaces of experience in Environmental Education at all levels of schooling and segments of society, promoting reflections and enabling actions to transform their realities.

Keywords: Environmental Degradation. Environmental Education. Youth and Adult Education. 


\section{PROCESOS DE URBANIZACIÓN Y DEGRADACIÓN AMBIENTAL URBANA: PROBLEMATIZACIÓN EN EL CONTEXTO DE LA EDUCACIÓN DE JÓVENES Y ADULTOS}

\section{RESUMEN}

Este artículo tiene como objetivo analizar cómo la educación ambiental se inserta en la educación de jóvenes y adultos a partir de la problematización de los procesos de urbanización y degradación ambiental urbana en el municipio de Capão da Canoa (RS). Los instrumentos utilizados para la recogida de datos fueron cuestionarios (objetivos y subjetivos) para los estudiantes, test de huella ecológica y debates. La implicación y participación de los alumnos aportó el movimiento de pertenencia, la reflexión histórica, social y medioambiental sobre su comunidad. La educación ambiental ofrece condiciones para educar para la ciudadanía, para el pensamiento crítico y político sobre los problemas sociales y locales que enfrenta esa comunidad. La prueba de la huella ecológica permitió un análisis comparativo con los países desarrollados, las condiciones sociales y ambientales de cada uno en relación con los estudiantes de la clase, ya que el resultado fue inferior a estos lugares donde el uso de los recursos naturales y la eliminación de residuos. Se concluye, a partir de las acciones desarrolladas, que el resultado más importante de esta investigación es el surgimiento de cuanto es necesario espacios de experiencia en Educación Ambiental en todos los niveles de escolaridad y segmentos de la sociedad, promoviendo reflexiones y posibilitando acciones de transformación de sus realidades.

Palabras clave: Degradación ambiental. Educación ambiental. Educación de jóvenes y adultos.

\section{INTRODUÇÃO}

Visto a realidade socioambiental atual, a nível nacional e regional, em que as atenções das pessoas estão voltadas às notícias que a mídia veicula a respeito do ambiente, uma vez este está sob 
impacto de nossas ações, é inquestionável a relevância da Educação Ambiental e emergente a mudança de atitude e hábitos em nossa sociedade. Capão da Canoa está localizada no Litoral Norte do Rio Grande do Sul, situando-se em uma região, conforme a Fundação Estadual de Proteção Ambiental, FEPAM (2000), riquíssima sob o ponto de vista ambiental, constituído por um cordão de lagoas litorâneas, banhados, barreiras de dunas e contrafortes da Serra Geral, sendo seus ecossistemas frágeis e raros.

A falta de diretrizes para a ocupação, intenso crescimento urbano e a falta de infraestrutura vem ocasionando impactos nos ecossistemas naturais na cidade de Capão da Canoa. O crescimento desordenado da cidade para a prática do veraneio, principalmente no período que compreende os meses de dezembro a março, vem trazendo sérios problemas, como ocupação de dunas, abastecimento de água inadequado suscetível a contaminação, poluição das águas superficiais e subterrâneas através do despejo do esgoto sem tratamento. Os processos de ocupação das zonas costeiras acabam por originar inúmeros conflitos socioambientais que vulnerabilizam os ambientes naturais, reduzem os serviços dos ecossistemas e provocam perdas de qualidade ambiental, que podem ser traduzidas em extinção de espécies, fragmentação de habitats, poluição, contaminações, entre outras.

O pertencimento do ser humano ao mundo-natureza possibilita uma educação voltada para a construção de um sentimento de pertencimento ao mundo e o desenvolvimento de uma consciência ecológica, que não só identifica problemas, mas reflete sobre possíveis alternativas de soluções. Para despertar o sentimento de pertencimento é importante possibilitar que o sujeito construa sua identidade, reconheça espaço ou lugar e assim possa potencializar, ressignificar suas ações e buscar uma sociedade menos desigual e com sustentabilidade. (COUSIN, 2010).

O perfil dos alunos da escola Luiz Moschetti, onde foi realizado o projeto, são homens e mulheres com pouca escolarização, que de alguma forma, em um tempo, foram evadidos da escola formal. Por considerar o contexto escolar como um potencial agente transformador da realidade, e as inúmeras experiências que tive nessa trajetória, algumas indagações surgiram e me inquietaram. 
Diante dessa realidade da Educação de Jovens e Adultos (EJA) e os processos de urbanização da cidade, fica o questionamento: $O$ que fazer para construir com estudantes da EJA uma realidade transformadora do contexto local atual? Quais ações podem produzir e multiplicar a educação ambiental a partir destes?

Assim esse artigo está organizado em quatro seções, a primeira aborda as bases teóricas e conceituais da educação ambiental que balizam o estudo. A seguir, é apresentada a metodologia do trabalho que é composta pela descrição das atividades de deram origem aos registros da pesquisa. Na seção seguinte, são analisados teoricamente os resultados (dados) produzidos e por fim são tecidas reflexões que sintetizam o estudo, apontando os possíveis desdobramentos da pesquisa.

\section{A EDUCAÇÃO AMBIENTAL E SEUS DESDOBRAMENTOS}

As bases teóricas e vertentes que constituíram o estudo da Educação Ambiental são inúmeras, segundo autores e olhares variados. Além de suas vertentes, buscou-se, nessa abordagem teórica, destacar determinados elementos relacionados as questões legais na Educação de Jovens e Adultos (EJA) e a gestão ambiental.

Educação Ambiental: suas vertentes

Nos últimos anos os problemas ambientais têm recebido muita atenção e relevância social, se tornando emergente a abordagem desse tema nas diferentes áreas de conhecimento e diferentes setores da sociedade, buscando soluções e também praticando a cultura do cuidado da casa comum. A Educação Ambiental vem como uma proposta para o enfrentamento dos problemas ambientais, e é um instrumento contribuinte na formação de cidadãos críticos em relação à sua realidade e conscientes de sua participação no ambiente (SORRENTINO et al., 2005). Segundo Layrargues (2004, p.7), a Educação Ambiental é:

[...] um vocábulo composto por um substantivo e um adjetivo, que envolvem, respectivamente, o 
campo da Educação e o campo Ambiental. Enquanto o substantivo Educação confere a essência do vocábulo "Educação Ambiental", definindo os próprios fazeres pedagógicos necessários a esta prática educativa, o adjetivo Ambiental anuncia o contexto desta prática educativa, ou seja, o enquadramento motivador da ação pedagógica.

Em relação aos conceitos e vertentes de educação ambiental podemos identificar dois grupos principais a conservadora e a Educação Ambiental crítica e transformadora. A Educação Ambiental conservadora tem como objetivo a mudança de comportamentos compatíveis a um determinado padrão idealizado de relações corretas com a natureza, com uma tendência a aceitar a ordem social estabelecida como condição dada, sem crítica às suas origens históricas. A EA Conservadora se alicerça na visão de mundo que fragmenta a realidade, simplificando e reduzindo-a, perdendo a riqueza e a diversidade da relação, educação focada no indivíduo. Essa perspectiva não contempla a transformação do indivíduo que se está inserido num processo coletivo de transformação da realidade socioambiental (LOUREIRO, 2004).

Conforme Loureiro (2004) a Educação Ambiental crítica e transformadora objetiva promover ambientes educativos de mobilização desses processos de intervenção sobre a realidade e seus problemas socioambientais, para que possamos nestes ambientes superar as armadilhas paradigmáticas e propiciar um processo educativo, enfatiza a educação como processo permanente e coletivo pelo qual agimos e refletimos, transformando a realidade de vida

Podemos compreender a educação crítica como essencialmente política, democrática, emancipatória e transformadora, analisando os problemas socioambientais fazendo com que o cidadão possa fazer a reflexão sobre o mundo e interferir no mesmo. De mesmo modo, a Educação Ambiental critica proporciona um ensino que se abre para a comunidade, com seus problemas locais sociais e ambientais, permeando uma educação crítica e política. 
A Educação Ambiental pode ser aprendida não somente na escola, mas levar em conta a relação dos estudantes com o meio em que vivem, buscando uma sensibilização e transformação da realidade.

Educação Ambiental: questões legais na Educação de Jovens e Adultos

No Brasil, a década de 80 é marcada pela definição da Política Nacional do Meio Ambiente definida pela Lei no 6.938/81 (BRASIL, 1981), que coloca a Educação Ambiental como instrumento que auxilia na qualidade ambiental necessária à vida, assim como também assegurar a dignidade humana. Nesse sentido, dispõe que a EA deve ser ofertada em todos os níveis de ensino e em programas específicos dirigidos à comunidade. O Ministério da Educação (MEC) inclui esta prática nos currículos escolares de $1^{\circ}$ e $2^{\circ}$ graus, possibilitando assim a inserção de temas ambientais locais e uma maior integração entre escola e comunidade como estratégia de aprendizagem (MEDINA, 2001).

No ano de 1994 é formulado o PRONEA (Programa Nacional de Educação Ambiental), e posteriormente a assinatura da Política Nacional de Educação Ambiental pela Lei 9.975/99 (BRASIL, 1999). A partir de então, passava-se a ter um instrumento legal para orientar o desenvolvimento da Educação Ambiental.

A Lei n. 9.795, de 27 de abril de 1999, que dispõe sobre a educação ambiental, e institui a Política Nacional de Educação Ambiental, em seu artigo $10^{\circ}$, afirma que "A educação ambiental será desenvolvida como uma prática educativa integrada, contínua e permanente em todos os níveis e modalidades do ensino formal" (BRASIL, 1999). Contudo, ela não é uma disciplina curricular obrigatória e pode ser abordada de diversas maneiras e de forma interdisciplinar levando em consideração a realidade de seus alunos.

$\mathrm{Na}$ Educação de Jovens e Adultos, diversos fatores devem ser levados em consideração, uma vez que as classes são bastante heterogêneas, sendo os estudantes de diversos níveis de aprendizado e com propósitos bastante particulares ao retornarem os estudos. Destaca-se que a EJA se torna oficial no Brasil, somente a partir de 
1945, com a aprovação do Decreto no 19.513, de 25 de agosto de 1945, contudo é a partir de 1960 que a EJA assume protagonismo impulsionado pelos estudos de Paulo Freire. Segundo Paiva (2002, p. 520) "a educação de jovens e adultos, em sociedades democráticas, assume a perspectiva da inclusão e esta inclusão, inevitavelmente, passa pela conquista de direitos". Ou seja, estamos nos referindo de um direito que durante muitas décadas foi negado ao povo brasileiro, um direito basilar que é o direito à educação.

Em sua proposta pedagógica Freire (1996) que o processo de alfabetização superaria o ensino de metódico de letramento e números, comumente sem sentido aos adultos. Ele propunha uma educação rica em sentido e significado que partisse do contexto social e cultural, uma educação que não fosse em si um fim e sim uma 'ponte' que transportasse ao mundo desvelado e real, em que os estudantes fossem responsáveis e pertencentes a esse mundo.

Nesse contexto, é importante tomar conhecimento do que o aluno de EJA sabe sobre meio ambiente, inserindo o aluno na discussão e procurar abordar assuntos que sejam facilmente visualizados e compreendidos por eles.

De acordo com Medina (2001, p. 17-18) a Educação Ambiental é um

processo que consiste em propiciar às pessoas uma compreensão crítica e global do ambiente, para elucidar valores e desenvolver atitudes que lhes permitam adotar uma posição consciente e participativa a respeito das questões relacionadas com a conservação e a adequada utilização dos recursos naturais, para a melhoria da qualidade de vida e a eliminação da pobreza extrema e do consumismo desenfreado.

Diante dessas considerações, a educação ambiental na Educação de Jovens e Adultos, pode ter contribuições significativas para a vida do estudante e construir uma consciência crítica em relação ao meio em que vivem, causando a transformação do mesmo. 
Educação Ambiental: gestão e crescimento urbano

Capão da Canoa, situada no estado do Rio Grande do Sul, recebe captação da água para abastecimento da lagoa dos Quadros, de acordo com Castro e Mello (2016), a lagoa dos Quadros recebe águas da lagoa Itapeva e do rio Maquiné. Tem importância regional para a gestão dos recursos hídricos ao fornecer água para abastecimento público dos municípios de Capão da Canoa e Xangrilá, abrigar comunidade de pescador artesanal e quilombolas em seu entorno e ainda servir de espaço de lazer. Sua área de preservação permanente apresenta irregularidades legais, como cultivos de arroz e solos expostos, silvicultura e a urbanização que vem se expandindo ano após ano. Em seu entorno, o cultivo de banana, condomínios de alto padrão, arrozais, falta de saneamento básico universalizado e o grande aumento da população no período de veraneio, são os principais fatores de risco para a disponibilidade e qualidade da água desta que é a segunda maior lagoa da Bacia do rio Tramandaí.

A Política Nacional de Resíduos Sólidos (PNRS) - Lei n 12.305, de 2 de agosto de 2010 propõe que os municípios devem estabelecer planos específicos para os diferentes serviços de saneamento (BRASIL, 2010). No Município de Capão da Canoa foi reformulado e atualizado o Plano Municipal de Saneamento Básico (PMSB) em 2016 (CAPÃO DA CANOA, 2016). Neste plano está caracterizado toda a geografia física, organização territorial político administrativa como plano diretor, demografia e crescimento populacional, área de proteção ambiental, indicadores sanitários, epidemiológicos e socioeconômicos. Na questão da estimativa de habitantes em períodos de inchaço populacional, este documento reporta um levantamento realizado pelo Plano da Bacia Hidrográfica do Rio Tramandaí, onde traz uma estimativa da população total no ano de 2004 para Capão da Canoa durante o inchaço populacional e no restante do ano.

Nesse estudo pode ser observado o aumento da população nestas épocas do ano, de dezembro a fevereiro. Estes dados só têm aumentado nos últimos anos, visto que para o ano de 2010 a população urbana de Capão da Canoa era de 41.830 habitantes, conforme dados populacionais do município de Capão da Canoa/RS, 
consultado no Instituto Brasileiro de Geografia e Estatística - IBGE, pelo plano Municipal de saneamento.

De acordo com um estudo realizado em 2016 pela Fundação de Economia e Estatística (FEE), trazem dados mais recentes sobre a população flutuante do litoral norte do Rio Grande do Sul, para o mês de janeiro de 2015 o estudo aponta para o Município de Capão da Canoa uma estimativa de 47.538 habitantes permanentes, 58.861 representando a média mensal da população flutuante no mês de janeiro e 106. 399 a população total para o mesmo mês, resultando num percentual de crescimento populacional de 123,8\%. Como aponta o estudo, a média da população no litoral norte pode sofrer uma profunda variação dentro de um período específico ou dia do ano, como fins de semanas de feriados, natal, ano novo entre outros, para o verão de 2014 e 2015 foi registrado pelo estudo uma população de 730 mil pessoas no período do Natal ao ano novo.

No plano Municipal de saneamento do município (CAPÃO DA CANOA, 2016) é citado que no Brasil, existe um Sistema Nacional de Informações sobre Saneamento - SNIS, que anualmente recebe informações dos municípios sobre os setores de água, esgoto e resíduos sólidos, mas que o município de Capão da Canoa não possuía informações operacionais no último relatório do SNIS de Resíduos Sólidos.

A gestão ambiental pode ser compreendida como um processo, o qual se inicia quando se promove adaptações ou modificações no ambiente natural, de forma a adequá-lo às necessidades individuais ou coletivas, gerando dessa forma ambientes nas suas mais diversas variedades de conformação e escala, (PHILLIPPI JR. et al., 2004). Ainda nesse contexto, segundo Leff (2001) a gestão ambiental, diz respeito à maneira de gerir a utilização dos recursos naturais, com vistas a minimizar os impactos gerados pelo homem enquanto ser social.

A gestão ambiental é um processo de mediação de interesses e conflitos entre atores sociais que agem sobre os meios físico-natural e construído. Este processo de mediação define e redefine, continuamente, o modo como os diferentes atores sociais, pelas suas práticas, alteram a qualidade do 
meio ambiente e também como se distribuem os custos e os benefícios decorrentes da ação destes agentes. (QUINTAS, 2006, p. 131)

Partindo desse contexto, a educação ambiental vem a ser uma importante ferramenta para que esses atores sociais possam, pelas suas práticas, modificar a sua realidade socioambiental. Desta forma, ações de educação ambiental dentro da escola no ensino de Jovens e Adultos (EJA), podem transformar e resolver conflitos socioambientais locais, envolver a participação da comunidade (coletivo) na gestão do uso dos recursos ambientais; na concepção e aplicação das decisões que afetam a qualidade dos meios físico, natural e sociocultural (QUINTAS, 2006).

Freire (1996) argumenta que a prática de ensino não se resume à transferência de conhecimentos e conteúdo, "mas criar possibilidades para a sua produção ou sua construção", e, portanto, defende a reflexão crítica, a relação teoria e prática. (FREIRE, 1996, p.47).

Dessa forma, o processo educativo deve superar a visão fragmentada da realidade, respeitar a pluralidade e diversidade cultural, proporcionar o diálogo com as áreas disciplinares e com os diferentes atores sociais envolvidos com a gestão ambiental.

\section{AÇÃO E REFLEXÃo}

O caminho escolhido para desenvolver a ação, realizada com os alunos da Educação de Jovens e Adultos (EJA) de uma Escola Estadual de ensino médio, situado na cidade de Capão da Canoa (RS), com as modalidades ensino fundamental, ensino médio e EJA do ensino médio. A EJA é ofertada no turno da noite juntamente com o ensino médio regular.

Os sujeitos dessa pesquisa, foram alunos da EJA, especificamente $\circ 3^{\circ}$ ano do EJA, que corresponde ao $3^{\circ}$ ano do ensino médio. A faixa etária dos alunos da EJA variam de 18 anos até 70 anos, as turmas eram mistas com alunos que interromperam os estudos há mais de 10 anos e outros apenas 1 ano. 
O perfil desses estudantes era em sua maioria moradores da comunidade local, alguns nativos e outros vindos de diversas cidades. Maior parte deles trabalhadores da construção civil, pedreiros, carpinteiros, pintores, eletricistas, empregas domésticas, zeladoras de prédios e casas, recepcionistas e vendedoras no comércio local.

Para tanto foram elaboradas cinco atividades de problematização que serão descritas a seguir.

- Atividade 1: Problematizando e apresentando o projeto: No primeiro encontro foi apresentado o projeto para os alunos da turma, mostrando os objetivos do trabalho. Para desenvolver a problematização junto dos alunos, foi feito um levantamento de alguns dados socioambientais. Para essa atividade os alunos trouxeram individualmente fotografias, reportagens e notícias que retratavam seu ambiente de trabalho, durante o ano e em época de veraneio.

- Atividade 2: Sensibilização e reconhecimento do lugar: No segundo encontro, os alunos se organizaram em um grande círculo na sala de aula em frente a um painel grande colocado no quadro, cada um fixou o seu material (fotografias, reportagens, etc.). Num segundo momento, cada aluno escolheu uma imagem ou material outro colega, que foi exposto, e lançado as perguntas: *Por que você escolheu registrar essa imagem ou notícia? *Que sentimentos te suscitaram? *O que você optaria em mudar ou permanecer nessa imagem ou notícia? As respostas foram registradas numa folha por cada um e depois, numa roda de debate, eles discutiram com o grupo. Por fim, a roda de debate foi trabalhada a compreensão de reconhecimento do lugar, onde estão os maiores focos que desencadeiam nos problemas socioambientais locais, fazendo assim uma reflexão sobre a transformação dessa realidade. 
- Atividade 3: Palestra com biólogo: Para essa atividade foi previsto uma conversa com um biólogo da área de gestão ambiental, como o profissional acabou não comparecendo, foi realizado uma palestra pela própria pesquisadora, que também é bióloga. Nesse encontro foi abordado questões como meios de descarte, coleta e destino de resíduos da construção civil e domésticos em condomínios de moradores, também foi mostrado um vídeo sobre exploração das florestas no Brasil chamado "A lei da água" No final da atividade também foi debatido com os alunos.

- Atividade 4: Levantamento de dados: Nessa atividade os alunos fizeram algumas ações dentro de seus ambientes de trabalho ou de sua comunidade local para promover a sensibilização. Nessa atividade cada aluno aplicou um questionário. As perguntas eram: * Você sabe para onde vai os resíduos produzidos no seu trabalho? * Você é orientado por algum gestor ou supervisor a fazer uma separação desses resíduos de acordo com algum critério ou lei? * Você considera que a poluição e degradação ambiental da cidade está apenas atrelada ao período de veraneio? * Na sua opinião, quem é responsável pelo lixo e poluição ambiental da cidade? As entrevistas serão entregues para a pesquisadora. Após as entrevistas realizadas, os alunos em sala aula leram suas entrevistas e relataram sua experiência em forma de uma roda de conversa no grupo.

- Atividade 5: Multiplicadores: transformando a realidade: Na última atividade foi realizado uma apresentação na sala de vídeo com o tema: Degradação ambiental na cidade de Capão da Canoa, junto da semana comemorativa do meio ambiente. Ao final dessa palestra, algumas reflexões acerca dos dados trazidos pelos questionários aplicados, trazendo para a turma o sentimento de pertencimento, entendo o que 
ocorre em sua volta e em sua comunidade socioambiental. Por fim foi entregue aos alunos uma folha com um teste com perguntas que no resultado constaria o tamanho de sua pegada ecológica. A Pegada Ecológica é uma ferramenta que quantifica a área que é necessária para produzir recursos e assimilar os resíduos gerados por certa população.

\section{DISCUSSÃO E COMPREENSÃO DOS RESULTADOS}

Nos itens a seguir, será apresentado os resultados que emergiram da ação, as reflexões a respeito das questões históricas e sociais da cidade de Capão da Canoa, o debate sobre os resultados do teste da pegada ecológica e por fim, análise dos dados e possíveis ações.

\section{Pertencimento e reflexões sócio-históricas de Capão da Canoa}

Iniciou-se a conversa com a temática e instigando os alunos a reflexão, ao decorrer da fala foi feito um mapa conceitual no quadro com as contribuições geradas na discussão. As turmas participaram efetivamente, cada qual queria falar sua opinião, descreviam e relatavam situações problemas de sua comunidade, de seus ambientes de trabalho. Os alunos ficaram bem entusiasmados. Podese perceber um grande envolvimento dos alunos, relatando suas histórias familiares, lembranças de um ambiente alterado e urbanizado. Um ponto interessante foi que nessa semana a escola estava trabalhando a semana de aniversário do Município, desta forma conseguimos trazer uma reflexão histórico-cultural, socioambiental da cidade de Capão da Canoa. Dentro desse material muita história e muita troca de experiências, os alunos de uma dessas turma tem idade bem acima da idade escolar para cada série, uma média de 30 anos de idade ou mais, chegando até 70 anos.

$O$ interessante nesse processo foi a troca, foi possível aprender muito sobre a história, sobre a cultura, sobre a realidade socioambiental com esses alunos, que na maioria, são nativos, filhos 
de nativos e que puderam contribuir para esse momento de discussão de maneira riquíssima. Um assunto relevante tratado no grupo foi sobre a situação do saneamento básico nos diversos bairros da cidade, na destruição das dunas na beira da praia retratada por fotos, reportagens e relatos. Foi possível fazer uma comparação sócio-histórica da situação da cidade, em relação ao ambiente em que estão inseridos, sobre como se sentem como parte integrador desse ambiente.

A Educação ambiental, em específico, ao educar para a cidadania, pode construir a possibilidade da ação política, no sentido de contribuir para formar uma coletividade que é responsável pelo mundo que habita (SORRENTINO et al., 2005, p. 287). Essas discussões estabelecidas pelos registros escritos, pelas discussões em grupo, que é muito importante buscar desenvolver nas pessoas o senso de pertencimento, quando estes sujeitos se sentem parte desse ambiente, o trabalho com a educação ambiental fica mais claro e tem mais resultados e alcançarmos um desenvolvimento ambiental, social e cultural, a educação ambiental vem a ser uma importante ferramenta para que esses atores sociais possam, pelas suas práticas, modificar a sua realidade socioambiental.

Cousin (2010) chama atenção para que o sentimento de pertencimento não seja confundido como territorialidade, que pode provocar conflitos, guerras e disputas, como podemos ver na atualidade, e a educação ambiental precisa ter uma perspectiva crítica em diferentes instâncias de diversidade. Por conta do atual modelo de sociedade, perdemos a capacidade de pertencimento, onde os olhos da sociedade e sujeitos estão direcionados ao capitalismo, conforme diz-nos Grün (2008, p. 92) que nós agimos e pensamos como se vivêssemos em "lugar nenhum", sem nos preocupar com o espaço, história, cultura e sujeitos.

Para despertar o sentimento de pertencimento é necessário que o sujeito construa sua identidade, reconheça espaço ou lugar e assim possa potencializar, ressignificar suas ações e buscar uma sociedade menos desigual e com sustentabilidade. Desta forma, ações de Educação ambiental como essa, podem transformar e resolver conflitos socioambientais locais, envolver a participação da comunidade (coletivo) na gestão do uso dos recursos ambientais; na 
concepção e aplicação das decisões que afetam a qualidade dos meios físico, natural e sociocultural. (QUINTAS, 2006).

Partindo da ideia de interdisciplinaridade, onde o aprender se torna significado quando o conhecimento adquirido se aplica à vida em seus diferentes aspectos e espaços. Foi registrado com fotografias o momento de discussão e reflexão nas turmas (Figura 1).

Figura 1- Mural de fotos contexto socioambiental Capão da Canoas

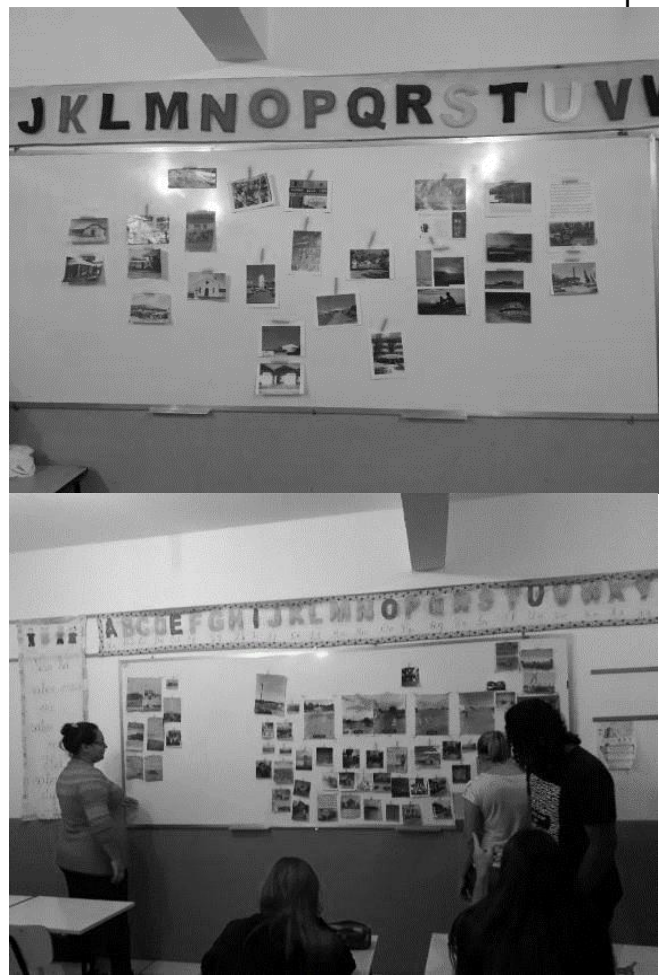

Fonte: Autores.

Sabendo que cada aluno tem sua realidade, espaços e lugares, histórias e pertencimentos diferentes, trazendo em comum entre eles a questão da degradação ambiental cometida pela prática do veraneio, trazendo o diálogo sobre seus lugares de trabalho, colegas, e em que eles próprios podem contribuir para ressignificar e transformar o ambiente que os cerca. 


\section{Determinando a Pegada Ecológica individual - Emergindo reflexões}

Após assistirem o documentário: "A lei da água", foi suscitando e despertando nos alunos uma consciência crítica a respeito dos temas discutidos anteriormente, tais como degradação dos ecossistemas locais. Após o documentário discutimos sobre nossas ações e foi aplicado uma atividade teste: Pegada Ecológica (Figura 2).

Figura 2- Palestra semana do meio ambiente e aplicação pegada ecológica

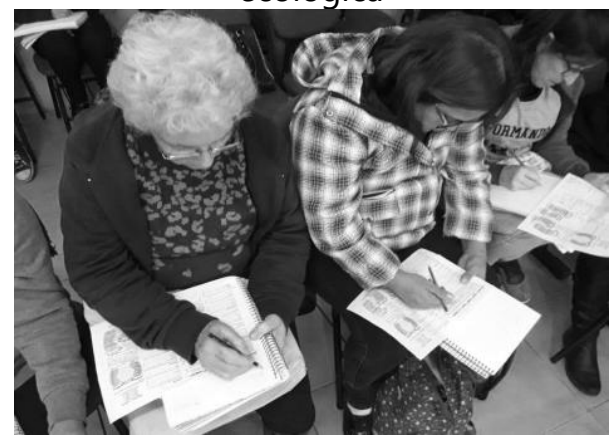

Fonte: Autores.

O conceito de Pegada Ecológica proposto por Dias diz que a Pegada Ecológica deve ser:

Um instrumento que permite estimar os requerimentos de recursos naturais necessários para sustentar uma dada população, ou seja, quanto de área natural é necessário para sustentar o consumo de recursos e a assimilação de resíduos de determinada população humana (DIAS, 2002, p.185).

A Pegada Ecológica do Brasil, de acordo com diferentes fontes, como o Relatório Planeta Vivo 2014, é de 2,70 ha/pessoa. $O$ valor desejável para a Pegada Ecológica individual varia em torno de dois hectares e meio. Porém, o valor encontrado na maioria dos países é muito superior. Na Alemanha, por exemplo, o valor da Pegada Ecológica é de 6 ha/pessoa, no Canadá 8,7 ha/pessoa, mas 
não se compara a países com as mais altas Pegadas Ecológicas, como os Estados Unidos, 12,5 ha/pessoa. Esses valores fazem perceber a distância de uma pegada sustentável, quiçá renovável. Para sustentar esse nível atual de consumo, é necessário mais de um planeta Terra (WWF, 2019).

Após aplicar o teste, cada aluno falou do seu resultado, foi discutido sobre o que podemos fazer para mudar a realidade. Foi constatado no resultado e discutido entre os alunos, que ao se comparar o resultado da pegada ecológica de países desenvolvidos e outros em desenvolvimento, percebe-se uma disparidade nos resultados, questiona-se que nem sempre o consumo, a produção de resíduos é uma escolha, e sim reflexo de uma sociedade muitas vezes desfavorecida, que não consome por não ter condições de consumir mais. Ainda foi debatido no grupo quais as possíveis ações, o que podemos fazer para mudar essa realidade.

O valor encontrado nos resultados da maioria dos alunos, entre 2 à 3,3 ha/pessoa, os fez perceber que estamos longe de uma Pegada sustentável, tendo em vista que o valor desejável para a Pegada Ecológica individual varia em torno de dois hectares e meio, e o percentual de resultados da maioria dos alunos ficou numa escala média de pontuação, significa que, ao continuar nesse nível de consumo de recursos naturais e bens materiais, eles estarão extrapolando a capacidade biológica da Terra.

Nesse contexto, a Educação Ambiental e a Pegada Ecológica se relacionam, para isso, são necessárias que ações sejam desenvolvidas no espaço escolar, tais como essas ações reflexivas que buscam a compreensão do ambiente e as relações existentes entre os alunos e o meio socioambiental, dessa forma, haverá o desenvolvimento da consciência reflexiva, crítica e ambiental desses cidadãos.

Em suas falas nos registros, os alunos participantes do projeto apontaram os problemas ambientais e possíveis soluções. A falta de saneamento básico, má qualidade da água e degradação dos ecossistemas litorâneos foram os problemas ambientais mais citados. A maior parte desses sujeitos reconhecem a interação e interdependência dos elementos do Meio Ambiente, e que a alteração em um dos elementos tem consequências para os demais. 
O que se pode notar na fala de grande parte dos alunos, foi a questão da importância do veraneio para manter as famílias, gerar trabalho e desenvolver a cidade. Em contrapartida, eles também destacaram que muito da degradação que se percebe vem desse período sazonal que aumenta o número da população e traz consequências para a cidade e o ambiente em que vivem pelo ano interino.

A cidade vive do veraneio, o que significa emprego para a população, porém o meio ambiente fica sujo, cheio de lixos e os córregos que deveriam levar a água da chuva para o mar, levam junto esgoto doméstico[...] isso tudo causa poluição da água, e ainda doenças nos moradores pela água contaminada. (Aluno 01)

Ao mencionarem de que modo podem ajudar, a disposição final do lixo em local adequado, a construção de estações para tratamento da água e esgoto foram a forma de contribuição mais mencionada. Ao trabalhar estas ações os alunos puderam entender a realidade socioambiental na qual o aluno está inserido, de forma a modificar paradigmas e de perceber o meio ambiente (DIAS, 2004). Para que que essa ação ocorra a educação ambiental deve assumir caráter crítico, além de se apresentar como emancipatória e transformadora (BRÜGGER, 2004), em busca de novos caminhos, que passam pelo pertencimento e participação social.

Grün (2008) defende que para problematizar questões ambientais é necessário "sentir em algum lugar". "Estar em um lugar", ter "a noção de lugar" é um modo de pertença ao mundo e é importante para nossa percepção primária e interconexões com o mundo não-humano. O que é evidente nas falas dos alunos, quando chamam atenção para os problemas locais que trazem consequências aos mesmos, a comunidade e também ao ambiente.

A percepção ambiental evidenciada pelos alunos da EJA investigados reflete as experiências pessoais de cada um, pois as respostas trazem atos e situações vivenciadas em sociedade. afirma que antes da realização de práticas de educação ambiental. Reigota (2010) afirma que é necessário que se conheça a percepção ambiental 
apresentada pelos indivíduos envolvidos, uma vez que a partir disto se pode realizar o movimento de sensibilização ambiental.

Poderiam colocar mais lixeiras nas ruas e na beira mar, fazer um centro de tratamento de esgotos para nossa cidade, fazer lugares onde pudessem abrigar os animais abandonados. (aluno 02).

Para Meghini (2005), a percepção ambiental nos permite tomar consciência do mundo:

Todo comportamento humano decorre de percepções, ou seja, as pessoas agem ou reagem de acordo como percebem e interagem com o meio ambiente (mundo) a sua volta. No entanto, diante de uma mesma situação-problema, evento ou objeto, cada pessoa tem uma experiência individual e única de percepção que depende de suas representações ou experiências anteriores, desenvolvidas durante toda a sua vida. (MEGHINI, 2005, p. 29)

O que fica evidente nos depoimentos e questionamentos dos alunos é que cada um tem uma experiencia individual do mundo a sua volta e diante deste pertencimento o aluno se torna capaz de enxergar sua realidade, sentir que faz parte desse meio e que dele retira sua fonte de sobrevivência, fazendo parte dele, ser tocado e sensibilizado.

Algumas falas apontadas sobre as soluções para os problemas ambientais locais se repetiram em vários participantes:

Chamar a atenção daqueles que poluem. (aluno 03)

Denunciar as pessoas que colocam o esgoto nos córregos. (aluno 04)

Fazer lixeiras na beira mar. (aluno 05)

Os registros dessas falas mostram que a grande maioria dos alunos conseguiu identificar os problemas ambientais locais. Além de identificar as questões ambientais conseguiram relacionar as questões sociais, entendendo que uma coisa é consequência da 
outra. Entendendo que o desenvolvimento busca uma melhora na qualidade de vida das pessoas, melhora dos aspectos econômicos, da saúde e bem-estar, das relações entre pessoas de uma comunidade, do contato com a natureza e outros. Carvalho (1992) ressalta que se a educação quer realmente transformar a realidade, não basta investir apenas na mudança de comportamentos, sem intervir nas condições do mundo em que as pessoas habitam.

Partindo desse princípio, a educação ambiental é uma ferramenta possibilitadora de transformação social e ambiental, onde os sujeitos envolvidos nesse processo possam identificar os problemas locais, refletir sobre as possíveis ações, implementar soluções para sua comunidade modificando e transformando a realidade, "A Educação Ambiental é a práxis educativa que é sim cultural e informativa, mas fundamentalmente política, formativa e emancipadora, portanto, transformadora das relações sociais existentes" (LOUREIRO, 2004, p. 31).

Por fim, o trabalho com educação ambiental promove reflexões, ações que modificam o sujeito, culturalmente, historicamente e politicamente. Modificam até que estes sujeitos sejam capazes de realizar ações que possam transformam sua realidade e a realidade de seu ambiente, ao qual se faz sentir parte e possa intervir no mundo.

\section{CONSIDERAÇÕES FINAIS}

Um dos resultados mais importantes desse estudo é o fornecimento de dados de quanto se faz necessário ações de Educação Ambiental em todos os níveis de escolaridade e segmentos da sociedade. Muitos dos sujeitos envolvidos na pesquisa, nunca sequer, foram questionados e instigados a refletir sobre problemas socioambientais locais, sobre as consequências e possibilidades de participação no desenvolvimento da sua comunidade.

A aplicação da ferramenta teste Pegada ecológica, instigou não só uma reflexão as questões de consumo individual e possíveis consequências para o planeta, mas também, ao comparar com o resultado de outros países, perceber que as relações de consumo e produção de resíduos estão diretamente ligadas as questões 
econômicas e sociais dos países, considerando que no Brasil muitos cidadãos não têm acesso a muitos meios de consumo, como transporte privado, alimentação, energia elétrica, saneamento básico, poder de compra em geral. Esses fatores, geram resultado de uma pegada ecológica muito abaixo da média dos países desenvolvidos.

Todas essas ações no contexto das atividades emergiram positivamente para que os sujeitos pudessem sentir-se pertencentes ao meio sócio-histórico, ambiental, refletirem seus problemas locais e pensar soluções para transformar, através da educação ambiental, a realidade. Por fim, destaca-se, ainda, que este estudo suscitou para a necessidade de investimento de políticas públicas que invistam na Educação de Jovens e Adultos, no sentido de propiciar condições de acesso e permanência a educação. A Educação de Jovens e Adultos é uma modalidade da educação básica que se destina a pessoas que tiveram pouca ou nenhuma oportunidade de escolarização regular, assim, problematizar a Educação Ambiental tem se mostrado como uma estratégia pedagógica de fomentar a discussão e o envolvimento desses adultos no processo do aprender.

\section{REFERÊNCIAS}

BRASIL, Lei no 12.305, de 2 de agosto de 2010. Política Nacional de Resíduos Sólidos- Disponível em: http://www. planalto. gov.br/ccivil_03/_ato200. Acesso em: 30 de outubro. 2018.

BRASIL. Lei n 6.938, de 31 de agosto de 1981. Diário Oficial [da] República Federativa do Brasil. Brasília, DF, 31 ago. 1981.

Disponível em: http://www.planalto.gov.br/ccivil_03/Leis/L6938.htm. Acesso em: 30 de outubro. 2018.

BRASIL. Lei nº 9.795 de 27 de abril de 1999. Dispõe sobre a EA, institui a Política Nacional de Educação Ambiental e dá outras providências. Diário Oficial [da] República Federativa do Brasil, Brasília, DF, 28 abr. 1999.

BRÜGGER, P. Educação ou adestramento ambiental? 3. ed. Chapecó: Argos, 2004. 
CAPÃO DA CANOA. Plano Municipal de Saneamento Básico. Capão da Canoa: Secretaria do Meio ambiente e planejamento/ Prefeitura Municipal de Capão da Canoa, 2016.

CARVALHO, I. C.de M. Educação Ambiental: a formação do sujeito ecológico. $3^{\text {a }}$ ed. São Paulo: Cortez, 1992.

CASTRO, D.; MELLO, R. S. P. (Org.). Bacia Hidrográfica do Rio Tramandaí: Atlas Ambiental. Porto Alegre: Via Sapiens. 2016. 179 p. COUSIN, C. S. Pertencer ao navegar, agir e narrar: a formação de educadores ambientais. Tese (Doutorado em Educação Ambiental) - Universidade Federal do Rio Grande. Rio Grande, 2010.

DIAS, G. F. Educação Ambiental: princípios e práticas. 9.ed. São Paulo: Gaia, 2004.

DIAS, G. F. Pegada Ecológica e Sustentabilidade Humana. São Paulo: Editora Gaia, 2002. 257p.

FEPAM. Diretrizes ambientais para o desenvolvimento dos municípios do Litoral Norte. In: Cadernos de planejamento e gestão ambiental - No 1. Brasil, RS, 2000.

FREIRE, P. Conscientização: teoria e prática da libertação: uma introdução ao pensamento de Paulo Freire. 3 ed. São Paulo: Centauro, 1996.

GRÜN, M. A importância dos lugares na Educação Ambiental. In: Revista Eletrônica do Mestrado em Educação Ambiental. Rio Grande: Universidade Federal do Rio Grande, volume especial, dez. 2008.

LAYRARGUES, P. P. Identidades da Educação Ambiental Brasileira. Brasília: MMA. 2004.

LEFF, E. Epistemologia Ambiental. São Paulo: Cortez, 2001.

LOUREIRO, C. F. B. Educação Ambiental Transformadora. In: LAYRARGUES, P. P. (Org.). Identidades da educação ambiental brasileira. Brasília: MMA, 2004, p. 65-84.

MEDINA, N. N. A formação dos professores em Educação Ambiental. In: BRASIL. Ministério da Educação e do Desporto. Secretaria de 
Educação Fundamental. In: Panorama da educação ambiental no ensino fundamental. Brasília, 2001.

MENGHINI, F. B. As trilhas interpretativas como recurso pedagógico: caminhos traçados para a educação ambiental.). 106 p., 2005. Dissertação (Mestrado) - Universidade do Vale do Itajaí, Itajaí, 2005.

PAIVA, V. P. Educação popular e educação de adultos. 4 ed. São Paulo: Loyola, 2002.

PHILLIPPI JR, A. et al. Uma introdução à questão ambiental. In: Curso de Gestão Ambiental. Barueri, SP: Manole, 2004.

QUINTAS, J.S. Introdução à gestão ambiental pública. Brasília: Ibama, 2006.

REIGOTA, M. Meio ambiente e representação social. São Paulo: Cortez, 2010.

SORRENTINO, M. et al. Educação ambiental como política pública. Educação e Pesquisa, São Paulo, v.31, n.2, p. 285-299, maio/ago. 2005.

WWF BRASIL. WWF. 2019. Disponível em: http://www.wwf.org.br. Acesso em 19 de janeiro de 2019.

Submetido em: Julho/ 2021.

Aceito em: Agosto/ 2021. 